\title{
Philosophy as Total Axiomatics: Serious Metaphysics, Scrutability Bases, and Aesthetic Evaluation
}

\begin{abstract}
What is the aim of philosophy? There may be too many philosophical branches, traditions, practices, and programs to admit of a single overarching aim. Here, I focus on a fairly traditional philosophical project that has recently received increasingly sophisticated articulation, especially by Frank Jackson (1998) and David Chalmers (2OI2). In Section I, I present the project and suggest that it is usefully thought of as 'total axiomatics': the project of attempting to axiomatize the total theory of the world. In Section 2, I raise a problem for the project that I call the 'problem of multiple axiomatizations'. I consider some initially alluring but ultimately unpromising approaches to this problem in Section 3. In Section 4, I defend a surprising approach to the problem, according to which competing axiomatizations of the total theory of the world are effectively evaluated for their aesthetic virtues.
\end{abstract}

KEYWORDS: serious metaphysics, scrutability, metaphilosophy, the aim of philosophy, total axiomatics

\section{Serious Metaphysics, Scrutability, and 'Total Axiomatics'}

What is the aim of philosophy? There are ways of understanding this question that render it somewhat uninteresting. Some philosophers appreciate the job security, some want to be famous; many value the ability to think clearly about anything. But beyond the various things philosophers happen to value, there is presumably also (at least one) distinctive thing of value that philosophical activity producessomething of value that can be achieved in no other way than by engaging in philosophical activity. That thing of value is the telos of philosophical activity, what philosophy itself aims at. As I will understand it, the question 'What is the aim of philosophy?' is to be answered by identifying the distinctive thing(s) of value that philosophy produces. (It is possible, of course, that there is more than one thing of value that philosophy produces; that would lead to pluralism about the aim of philosophy. There is also the prima facie possibility that nothing of value is produced by philosophical activity; that would result in a sort of nibilism about the aim of philosophy.) 
Very likely, philosophy includes too many traditions, branches, programs, and practices to admit of a single overarching aim in this sense. Here, I focus on one central strand in traditional philosophical practice, one that in recent years has received increasingly sophisticated articulation, most notably by Frank Jackson and David Chalmers. In From Metaphysics to Ethics, Frank Jackson (I998) expresses the basic idea thus:

Metaphysics is about what there is and what it is like. But it is not concerned with any old shopping list of what there is and what it is like. Metaphysicians seek a comprehensive account of some subjectmatter-the mind, the semantic, or, most ambitiously, everything-in terms of a limited number of more or less basic notions. (Jackson I998: 5)

Jackson calls this project 'serious metaphysics'. Serious metaphysics has two crucial features: 'it is discriminatory, and it claims completeness' (I 998: 27). At the end of serious-metaphysical inquiry, if you will, we would have a complete theory of the world, a theory that leaves nothing unaccounted for. But despite leaving nothing unaccounted for, the theory would list only a proper subset of all truths, thus discriminating in favor of certain truths. For example, while it might list 'Jimmy is blue all over', and perhaps also 'Nothing can be both blue all over and red all over', it will not list 'Jimmy is not red all over'; while it might list 'Julius is a dog' and 'Dogs are mammals', it will not also list 'Julius is a mammal'. The reason is that it does not need to list those extra truths to ensure that nothing is left unaccounted for. Thus, the theory discriminates between truths it explicitly cites and truths it does not, and yet claims completeness in the sense of leaving nothing unaccounted for.

Let us call the statements the theory finds it must list 'fundamental' and those it finds unnecessary to list 'derivative'; and likewise let us call the notions appearing in the fundamental statements 'fundamental notions' and those appearing only in derivative statements 'derivative notions'. (I use 'statement' as conveniently ambiguous between proposition and sentence, and 'notion' as conveniently ambiguous between concept and word. In either reading, a notion is a constituent of a statement.) The above characteristics of serious metaphysics may now be stated as follows:
COMPLETE
Serious metaphysics attempts to produce a total theory of the world, that is, a theory of everything.
DISCRIMINATE Serious metaphysics discriminates between fundamental and derivative statements (and notions).

Jackson argues from these two claims to a third he calls 'entry by entailment'. ${ }^{\mathrm{I}}$ The claim is that any statement $S$ not explicitly cited by a serious-metaphysical theory $T$

\footnotetext{
I That COMPLETE and DISCRIMINATE suffice for 'entry by entailment' is explicitly stated by Jackson (I998: 39). The argument from the former to the latter takes up most of chapteri of the book.
} 
can still qualify as a truth by T's lights if, and only if, $S$ is entailed by the statements $T$ does explicitly cite. In other words, $T$ 's derivative statements are all and only those statements entailed by T's fundamental statements. Accordingly:

ENTAIL The relationship between fundamental and derivative statements in the total theory of the world is that of entailment.

Serious metaphysics is fully characterized by the conjunction of COMPLETE, DISCRIMINATE, and ENTAIL. That is, any project that abides by all three claims qualifies as (a bit of) serious metaphysics. Accordingly, a product of seriousmetaphysical inquiry can be unsatisfactory in three main ways: it may fail to account for everything, fail to draw a satisfactorily compact group of fundamental truths, or fail to secure the entailment of derivative truths from fundamental ones.

Essentially the same project is developed in greater detail in David Chalmers's (2012) Constructing the World. Chalmers goes beyond Jackson in arguing for the central presupposition of serious metaphysics, namely, that there exists a small group of truths from which all others can be derived. In addition, for Chalmers the relationship between fundamental and derivative truths is not that of entailment but that of 'scrutability':

There is a compact class of truths such that all truths are a priori scrutable from truths in that class. We can define a priori scrutability [as follows]: a sentence $S$ is a priori scrutable from (or a priori entailed by) sentences in a class $\mathrm{C}$ iff $\mathrm{S}$ can be logically derived from some members of $\mathrm{C}$ along with some a priori truths. Given weak assumptions, the right-hand side is equivalent to the claim that there is a conjunction $\mathrm{D}$ of sentences in $\mathrm{C}$ such that the material conditional 'If $\mathrm{D}$, then $\mathrm{S}$ '... is a priori. (Chalmers 201 2: 7)

It looks like ' $p$ is scrutable from $q$ ' means that the conjunction of $q$ and all a priori truths deductively entails $p$. Accordingly, the central presupposition behind the project of identifying the 'scrutability base' of our theory of the world is that there exists such a base:

SCRUTABLE There exists a compact set of truths that, in conjunction with all a priori truths, deductively entail all truths.

Whereas ENTAIL required fundamental truths to entail derivative truths by themselves, SCRUTABLE requires only that they do so when conjoined with all a priori truths. ${ }^{2}$ Otherwise, however, the projects are essentially the same.

The term 'compact' in SCRUTABLE is intentionally imprecise: the project does not depend on there being a specific number, or even an upper threshold, of

2 In this respect, SCRUTABLE is less demanding than ENTAIL. In another respect, however, ENTAIL is less demanding, at least as intended by Jackson. For Jackson (I998: 25) allows that not all entailment may be a priori. For the most part, I will ignore this otherwise important measure of leniency. 
fundamental truths. Rather, the project's goal is to articulate the bare minimumwhatever it is-of fundamental truths required to entail or 'scrute' all other truths. Jackson writes:

By serious metaphysics, I mean ... metaphysics that acknowledges that we can do better than draw up big lists, that seeks comprehension in terms of a more or less limited number of ingredients.... How big a list of basic ingredients we need, and even whether there is an urset, are matters open to debate; what seems to me obvious is that we can set some limits on what we need... and serious metaphysics is the investigation of where these limits should be set. (Jackson I998: 6, my italics)

That is, serious metaphysics should be not just discriminatory but maximally discriminatory. Its identified set of fundamental truths, or 'scrutability base', should be minimal: 'a class of sentences $\mathrm{C}$ such that $\mathrm{C}$ is a scrutability base and no proper subclass of $C$ is a scrutability base' (Chalmers 20I 2: 2I, my italics).

Put this way, the project bears patent resemblance to axiomatization projects in mathematics. Given a set of statements recognized as the truth, the whole truth, and nothing but the truth in some domain (say, number theory), axiomatics is concerned to identify the minimal subset thereof from which the rest can be derived (and nothing else can). In general, an axiomatized mathematical theory exhibits both of Jackson's features: (i) it is discriminating in designating a small subset of all statements in the relevant domain as axioms, and (ii) it is complete in ensuring that every statement $S$ in the domain is such that the axioms entail either $S$ or $\sim S$.

In mathematics, axiomatization is typically attempted for specific subdomains of mathematics. But here, too, a more ambitious version can be sought for the whole of mathematics, as in the work of the Bourbaki research group (see Bourbaki I970). The measure of progress in this area is the minimization of the number of axioms and, even more centrally, of the primitive notions needed to express them. Thus, Pasch (I 882) managed to define all geometric notions in terms of four fundamental ones (point, segment, plane, superposition), but it was a measure of progress when Peano (I889) reduced the number to three (point, segment, motion) and then Pieri (I900) further reduced it to two (point, motion). Progress in carrying out the Jackson-Chalmers project would presumably take a similar form, minimizing the subset of all truths that have to be treated as fundamental and/or the set of fundamental notions needed to express them.

The parallel between the two projects is thus evident. The main difference is that whereas the mathematical project is concerned with a limited domain, its philosophical counterpart is ultimately concerned with all truths-the 'theory of everything'. For this reason, we may call the philosophical project total axiomatics: an attempt to axiomatize the total theory of the world.

Another important difference concerns the epistemic status of axioms. Mathematicians tend to vacillate between two extreme approaches: one casts axioms as not just true but self-evidently and indubitably so; the other sees axioms 
as neither true nor false but as arbitrary stipulations we are only interested in to know what follows from them (see Blanché I955; Schlimm 2013). In the philosophical project of total axiomatics, in contrast, we do commit to the truth of the statements in our 'scrutability base' - they are fundamental truths, after all-but it is not built into the project that we must treat them as self-evident or indubitable.

Nor is it built into the project that the total theory of the world is the scientific theory of the world. Even if we are tempted to take the natural sciences to deliver its core, the total theory may also include truths that do not come from the sciences: truths about relationships between natural sciences (biology and chemistry, say), truths from the humanities (literary generalizations, say), truths about normative matters (moral truths, for example), and so on. It is an open question, of course, whether there are moral, literary, or interscientific truths, and a further question whether these might be entailed or scrutable from natural-scientific truths. But the point is that total axiomatics as such is silent on these questions. It is thus compatible with a view that allows nonscientific truths in the scrutability base. An interesting implication is that while the main mandate of philosophy as conceived in this project is to axiomatize total theory, a subsidiary mandate may be to ensure that the theory is indeed total. For example, if, contrary to metaethical expressivism, there are moral truths, then we may have to engage in normative ethics-a branch of philosophy-to discover those. In this capacity, normative ethics is contributing 'theorems' to our total theory of everything rather than promoting the axiomatization of that theory. (Normative ethics clearly involves also the axiomatization of normative theory: a Kantian who adds the categorical imperative to her 'scrutability base', holding that all normative truths are entailed by the conjunction of the categorical imperative and nonnormative truths, clearly engages in axiomatizing total theory. In addition, however, it makes a contribution to the theory's axioms.)

There is no doubt that total axiomatics is a philosophical project, a project of philosophy. Suppose for the sake of argument that all truths are entailed by microphysical truths. Then it would be the microphysicist's prerogative to tell us the fundamental truths. But it would not be her prerogative to tell us that they are the fundamental truths. That is the philosopher's job. No microphysicist attempts to show that the truths of 'political science' are entailed by (or scrutable from) the truths of microphysics. The microphysicist does not concern herself with the truths of political science at all, much less with their relationship to microphysics. Or more accurately: any microphysicist who did concern herself with the truths of political science would not be doing so in her capacity as microphysicist.

Jackson and Chalmers seem to think something a little stronger: perhaps not quite that total axiomatics is the only project of philosophy, but certainly that it is a central, organizing project of philosophy-at least of a certain traditional form of analytic philosophy. This is not intended as a sociological thesis about what most philosophers would claim they are doing. Rather, the thesis is that many central philosophical issues, problems, and debates either (a) pertain directly to the attempt to find a minimal scrutability base for the 'theory of everything' or (b) have been reached through a series of dialectical twists and turns whose starting point pertained directly to that attempt. One way to show that total axiomatics 
is an organizing project of philosophy in this sense would be to go through as many philosophical problems as possible and show how they can be conceived of as concerning the identification of fundamental truths. This would probably require a book or several, though see Chalmers (20I 2: ch.6) for a 'comically brief' (20I 2: 259) discussion of fifteen-odd central philosophical issues. A different way to show the centrality of total axiomatics would be to go over some of the most prominent and familiar characteristics of workaday philosophical practice and show how total axiomatics rationalizes their prominence. These characteristics include careful examination of arguments and objections, clarification and analysis of central notions, rife appeal to thought experiments and intuitions they elicit, marked sensitivity to parsimony considerations, a general concern for ontological commitment, a premium on armchair reasoning, and more. If such characteristics can be shown to fall out of the features of axiomatization projects in general and total axiomatics in particular, this would underscore the central role of total axiomatics in philosophy. This too would require a very lengthy demonstration; elsewhere (Kriegel 20I 5 ) I present a preliminary case, no less comically brief than Chalmers's, indicating how the aforementioned characteristics of philosophical practice might be recovered by total axiomatics.

\section{The Problem of Multiple Axiomatizations}

The project of total axiomatics, indeed traditional analytic philosophy and its practice, are open to a variety of external critiques-from naturalistic philosophy, experimental philosophy, postmodernism, and any number of other philosophical approaches and paradigms. Here I want to bracket such external critiques and consider a problem that arises from within the framework of total axiomatics. I call it the 'problem of multiple axiomatizations'.

In mathematics, it often happens that different axiomatic systems describe the same domain. Sometimes the alternative systems are nonequivalent, in that the axioms yield contradicting theorems-as in Hilbert's axiomatization of Euclidean geometry and Lobachevsky's axiomatization of non-Euclidean geometry. These are competing axiomatizations only in the following sense: for any statement $S$ for which the first entails either that $S$ or that $\sim S$, the other does as well (and vice versa). That is, the two axiomatizations 'take a stand' on exactly the same domain of statements, and to that extent describe the same domain of phenomena. Sometimes, however, different axiomatizations compete in the stronger sense that they are equivalent: they assign the same truth value to every $S$, yet designate different subsets of these putative truths as axioms. An example of this is Hilbert's and Tarski's competing axiomatizations of elementary Euclidean geometry. Here the two axiomatizations compete not only in describing the same domain, but in describing it in the same way. Not only do they 'take a stand' on the truth values of the same statements, they take the same stand.

An analogous phenomenon is bound to attend total axiomatics, though certain care is needed in articulating the analogy. The total theory of the world is just a body of statements, and from a purely formal point of view, the entailment 
relations within a body can often be organized in different ways. Consider the following body of statements, which is a fragment of the total body of statements describing the world: let $u \oplus d$ stand for 'Every electron has either spin up or spin down' (I use ' $\oplus$ ' as the symbol for XOR, the exclusive-disjunction operator); and let $u$ stand for 'Alec has spin up', and $d$ stand for 'Alec has spin down' (where Alec is the name of an electron). From a logical standpoint, $u$ is scrutable from $\sim d$ and $u \oplus d$ just as much as $\sim d$ is scrutable from $u$ and $u \oplus d$. That is, (at least) two equivalent axiomatizations of this body of statements are available. However, each axiomatization generates new second-order truths: the first generates the secondorder truths ' $u$ is fundamental' and ' $\sim d$ is derivative', whereas the second generates the (incompatible) second-order truths ' $\sim d$ is fundamental' and ' $u$ is derivative'. Since total axiomatics covers the totality of truths, it would seem that the total theories of the world one obtains by adopting these two different axiomatizations would be different. If so, the two axiomatizations will not be equivalent in the strong sense of assigning the same truth values to all the statements in their domain.

However, something similar enough to equivalence in this strong sense would still be the case: the two axiomatizations may be equivalent not only with respect to the domain of statements to which they assign truth value, but also with respect to the truth values they actually assign to all statements whose truth-value assignment is independent of the exercise of total axiomatics. Every statement in a total theory of the world is assigned a truth value by the theory. Some statements are assigned a truth value by the part of the total theory known as nuclear physics, some by the part known as organic chemistry, some by that known as social psychology, and some by total axiomatics (e.g., statements of the form ' $p$ is fundamental' and ' $q$ is derivative'). Call the proper subset of statements in the total theory whose truth-value assignment pertains to the total-axiomatic part of the theory the 'totalaxiomatic statements'; and call the members of that proper subset's complement the 'total-axiomatics-independent statements'. Then two axiomatizations of the total theory of the world can be equivalent in a restrictedly strong sense in case they assign the same truth value to all total-axiomatics-independent statements. The total theories that differ only in whether they take $u$ or $\sim d$ to be fundamental are equivalent in this restrictedly strong sense.

Sometimes, we might have a reason to prefer one axiomatization over another because the notions appearing in certain statements feel more fundamental than those appearing in others. This move grounds the fundamentality of statements in the fundamentality of notions or statement-constituents. Here too, however, it is worth noting that many groups of notions are interdefinable, and from a purely formal standpoint the decision on which to treat as fundamental is arbitrary. If our definition of a bachelor is ' $x$ is a bachelor iff $x$ is an unmarried man', then formally speaking nothing prevents us from defining a man through ' $x$ is a man iff: if $x$ is unmarried, then $x$ is a bachelor', and indeed being unmarried through ' $x$ is unmarried iff: if $x$ is a man, then $x$ is a bachelor'. Thus any two of these three notions (plus logical vocabulary) can be used to define the third. In the same vein, we can imagine a troika of concepts $C_{I}, C_{2}$, and $C_{3}$, such that (i) at least two must appear in fundamental truths and (ii) any pair can be used to define the third. Then 
other things being equal, our total theory of the world would admit of at least three equivalent axiomatizations.

This is not a merely 'theoretical' possibility but infects the philosophical project of total axiomatics regularly. Consider the central ontological dispute over the comparative fundamentality of objects, properties, and states of affairs. It seems unnecessarily profligate to treat all three entities as fundamental: the object $a$, the property $F$, and the state of affairs $F a$. At the very least, we are inclined to take objects and properties as fundamental and account for states of affairs in terms of them: $F a$ is just the appropriate coming-together of $a$ and $F$. Many ontologists have been tempted to go further and admit only one fundamental here. Some nominalists have construed properties as sets of resembling objects: $F$ is just the set of objects that relevantly resemble $a$ (and $F a$ is nothing but $a$ 's membership in that set). Inversely, some bundle theorists have construed objects as sets of coinstantiated properties or of compresent property-instances: e.g., $a$ is just the set of relevant property instances (and $\mathrm{Fa}$ is nothing but $F$ 's membership in that set). There is also the view, sometimes called factualism (Skyrms I98I), that assays both objects and properties as two different sets of states of affairs: $a$ is a set of compresent states of affairs while $F$ is a set of relevantly resembling states of affairs. This kind of dispute will be reflected in the truths each ontologist takes as fundamental. The nominalist derives ('scrutes') ' $a$ is $F$ ' from ' $a$ is a member of the Fs', for instance, while the factualist goes the other way round, deriving ' $a$ is a member of the Fs' from ' $a$ is $F$ ' (or perhaps from ' $a$ 's being $F$ obtains'). If nothing else, it is clear that ' $a$ exists' is fundamental for the nominalist but not for the bundle theorist or factualist, ' $F$ is instantiated' is fundamental for the bundle theorist but not the nominalist or the factualist, and ' $a$ 's being $F$ obtains' is fundamental for the factualist but not the nominalist or bundle theorist. Note that all sides agree that $a$ is $F$, that $a$ exists, that $F$ is instantiated, that $a$ 's being $F$ obtains, and so on. Their disagreement is only on which of these should be treated as fundamental. That is, they offer incompatible but equivalent (in the restrictedly strong sense) axiomatizations of the same body of truths. ${ }^{3}$

Many traditional philosophical debates take this form: they are debates on which among multiple axiomatizations of total theory should be adopted (Castañeda I 980 : ch.4). Think of the different ways of going on the issue of fundamentality with respect to such clusters of notions as causality, laws, counterfactual dependence, funds of dispositions, and so on-or good, right, reason, ought, and so on.

What this means is that the traditional project of analytic philosophy we have been considering cannot be characterized simply as the axiomatization of total theory. For much of what philosophers do as part of this project goes beyond the axiomatizing of total theory and pertains rather to the choice among axiomatized total theories. Accordingly, serious metaphysics (or 'total axiomatics') is not fully characterized by the conjunction of COMPLETE, DISCRIMINATE, and

3 Admittedly, philosophers disagree not only on such matters as whether the Fs are fundamental, but also on such matters as whether there are Fs at all. For example, the nominalist above does not only claim that properties are derivative upon objects but also-relatedly—that there are no universals. But such statements as 'There are no universals' are also the products of total axiomatics; accordingly, they are not total-axiomatics-independent statements. 
ENTAIL (or SCRUTABLE) - contrary to what was asserted in Section I. That characterization requires supplementation. We now turn to consider some potential supplementations.

\section{Some Unpromising Approaches to the Problem}

One way to approach the problem of multiple axiomatizations is to construe alternative axiomatizations as competing 'philosophical systems' and use the standard canon of theory choice to pick the 'best' among them. While philosophical systems are often empirically equivalent, they tend to differ in their 'theoretical' or 'superempirical' virtues: parsimony, simplicity, elegance, unity, conservatism, testability, fecundity, modesty, and so on. If axiomatization $A_{I}$ scores higher on these than $A_{2}$, we thereby have reason to prefer it.

There is no question that appeal to theoretical virtues in arguing for (indeed choosing) a philosophical theory is another familiar characteristic of philosophical practice. However, it is less clear what kind of choice this is. In particular, it is unclear that it is choice of the theory most likely to be true. For it is highly questionable that any of the theoretical virtues is truth-conducive, especially in the philosophical context (Kriegel 20I3). Although a full case for this cannot be made here, some preliminary remarks might be suggestive. First, some virtues, such as unity or coherence, have been formally shown to be non-truth-conducive (Bovens and Hartmann 2003). The formal demonstration only confirms an intuitive suspicion: the contents of The Brothers Karamazov are incredibly coherent at many levels, but do not for all that correspond to any objective fact. Secondly, other virtues, such as fecundity and testability, are clearly valuable on heuristic rather than truth-indicative grounds. A theory is fruitful or fecund to the extent that it opens up new avenues of inquiry and energizes research in the relevant area. While this makes the theory more exciting, it does nothing to suggest the theory is true. Thirdly, likewise, a theory's 'elegance', whatever that amounts to (more on that later), can only be truth-conducive if the world represented by the theory is elegant-but we have no direct evidence one way or the other on this. Fourthly, other virtues, such as modesty, are clearly truth-conducive but do not apply to total axiomatics. A theory is more modest the fewer claims it makes, and other things being equal, fewer claims means fewer ways of going wrong. But recall that an axiomatic system is complete only when for every statement $S$ in the relevant domain, the axioms entail either that $S$ is true or that $S$ is false. When the relevant domain is everything, then all complete axiomatic systems will assign to every statement either $T$ or $F$. Therefore, they will all make the same number of claims and hence be equally modest. Accordingly, modesty cannot discriminate between alternative axiomatizations of total theory.

What about the queen virtue, parsimony? In scientific contexts, parsimony often serves to indicate likely truth. Consider this piece of reasoning from evolutionary biology: both humans and monkeys have tailbones; if humans and monkeys have no common ancestry, the tailbone would have to originate twice; if they have common ancestry, it only has to originate once; the latter hypothesis is thus more parsimonious than the former, and more likely to be true (Sober 2009). The idea 
here is that the occurrence of two events is less probable than the occurrence of one (other things being equal). Suppose the probability of $E_{I}$ occurring is 70 percent and that of $E_{2}$ is 50 percent. Then the probability of both occurring is 35 percent-lower than either separately. Accordingly, the single-event hypothesis is more probable than the dual-event one, so parsimony tracks likely truth. Observe, however, that the kind of parsimony invoked here is not the philosophical kind. Both hypotheses posit the same kinds of entities-humans, monkeys, tailbones, originations. But while philosophers may rightly debate whether there are dogs or only particles arranged dog-wise, they may not (qua philosophers) debate just how many dogs or how many particles there are-that is the zoologist's or physicist's province, not the philosopher's. For the philosopher's brand of parsimony to be truth-conducive, it would have to be the case that a philosophical system citing fewer kinds of entities is more likely to represent correctly the number of kinds of entities the world actually contains. We may put this by saying that philosophical parsimony's truthindication depends on the principle of the barrenness of nature: the world contains very few entities. Unfortunately, this principle suffers from a distinct dearth of evidence. More deeply, philosophers clearly do not cite parsimony because they believe in the barrenness of nature. Parsimony does something for them, but what it does is not to give them confidence that they have accurately represented the independent number of kinds of entities the world contains.

In mathematics, the choice among equivalent axiomatizations is entirely pragmatic-we go with whatever works best in a given context and for given purposes. One could adopt a sort of metaphilosophical pragmatism that would apply the same stance to total axiomatics. Carnap (I950) notoriously took this approach with respect to questions of ontological commitment. For Carnap, we can adopt an 'object framework' and ask within this framework whether there are properties or states of affairs, and we can adopt a 'state-of-affairs framework' and ask within it whether there are objects or properties. But it makes no sense to then ask whether there are objects or states of affairs from a completely neutral, framework-free standpoint. There are no objective facts of the matter that would answer such a question. The only thing we can do is make a pragmatic choice between the object framework and the state-of-affairs framework, that is, to choose whichever framework works best for us given our purposes and interests, whatever they may be. On this view, different axiomatizations of the total theory of the world cannot be compared for likely truth, but they can still be compared-for their benefits, their utility, or something like that.

A Carnapian approach to the problem of multiple axiomatizations has the virtue of paralleling the standard approach in mathematical axiomatics. It is the approach adopted by Chalmers, who is alive to the problem of multiple axiomatizations: 'For most of our purposes, the existence of multiple scrutability bases is not a problem. Carnap himself held a pluralistic view on which there are many equally privileged bases that we can choose between only on pragmatic grounds' (Chalmers 20I2: 25). Accordingly, for Chalmers the choice between an object framework, a property framework, and a state of affairs framework is purely pragmatic. More generally, 
there are no 'objective answers to the basic questions of ontology' (Chalmers 2009: 77).

There is an important problem with the pragmatic approach, however. When we say that one should adopt whichever axiomatization 'works best', the immediate question is 'works best for what?' The Carnapian answer is something like 'works best for the conduct of inquiry', with the relevant inquiry typically construed as scientific. In mathematics, too, an axiomatic system is useful to the extent that it allows us to prove suspected theorems, leads in the direction of new theorems, and so on. But this purely heuristic basis for choosing an axiomatization makes sense only so long as inquiry is ongoing. If we indulge for a moment the notion of the total theory of the world at the end of inquiry, it is clear that this final total theory would also admit of multiple axiomatizations. Yet, there would be no further inquiry (scientific or otherwise) for any axiomatization to abet. To the extent that the philosophical project of total axiomatics tends toward a fully axiomatized complete theory of the world, it would be useful for us to know what to do with the multiple axiomatizations that would be available to us even when our theory of the world will be complete.

One approach here might be a kind of celebratory pluralism of 'let a thousand flowers bloom'. The idea would be that philosophy shows us many different ways in which the world could be conceived of systematically, in a unified, well-ordered fashion. It reveals the many different bedrocks the world may have consistently with everything we know about it. This multiplicity is something to delight in, from the perspective under consideration. In bringing out the multiplicity, philosophy opens us up to novel, unusual, wonderful ways of making sense of the world as a whole. Perhaps it can even be said to liberate us from the monopolistic grip of natural language or folk theory, which encode particular ways of systematizing the world. For example, while the subject-predicate structure of simple public-language sentences suggests a metaphysic of objects and properties, nominalism and the bundle theory feed into axiomatizations of total theory that show us other ways of coherently thinking of the fundamental structure of reality, ways less natural to us but correspondingly more exciting to the intellectual imagination.

There is much charm to this cheerful pluralism. At the same time, granted that the theoretical virtues cannot help us evaluate competing axiomatizations for truth, it does not yet follow that they cannot help us evaluate them at all. There may well be some value $V$, other than truth, such that we may evaluate competing axiomatizations of total theory for $V$-ness, rather than remain entirely nonjudgmental about them in the manner of our charming pluralist.

More specifically, observe that philosophers do in fact evaluate philosophical systems, and do so by appeal to the theoretical virtues. So if some $V$ could be identified such that all or most theoretical virtues are $V$-conducive, it would turn out that philosophers in effect are evaluating systems for $V$-ness. This may be so even if it is not transparent to philosophers that $V$-ness is what they effectively evaluate competing philosophical systems for. With this in mind, I suggest the following bit of intellectual reverse-engineering: let us discover what philosophers in effect evaluate competing systems for by considering which value $V$ is (or which 
values $V_{I}, \ldots, V_{n}$ are) enhanced by the criteria for theory choice philosophers use in practice.

\section{Multiple Axiomatizations and Aesthetic Value}

What is the meaning of life? Sadly, I have no answer to offer. I do note, however, that notions such as happiness, fulfillment, well-being, flourishing, and eudaimonia are adduced in relevant discussions. Sometimes these terms are used in substantive accounts of the point of life, other times as mere labels for whatever it is we want to get out of life. Let us use 'happiness' in this second way, as a mere label for whatever turns out to be the meaning of life. Surely it would be nice if an axiomatization of total theory enhanced happiness in this sense! Since such an axiomatization's happiness-enhancing capacity is valuable to us, we can evaluate competing axiomatizations for their relative success in enhancing happiness. And, really, what could we possibly want out of anything beyond that it enhance our happiness in this especially wide sense?

To some extent, this line of reasoning is perfectly cogent-we can, indeed, evaluate competing axiomatizations of total theory for their happinessenhancement. But it is noteworthy that we can evaluate anything for its happinessenhancement. In that respect, evaluation of competing axiomatizations of total theory for happiness-enhancement is not specifically philosophical evaluation. It does not evaluate the competitors qua products of philosophical activity. Accordingly, it does not illuminate the role of parsimony, simplicity, unity, and elegance in the actual practice of evaluating competing philosophical systems. After all, it is not clear how (or even that) having parsimonious theories, or unified ones, tends to make us happier. It would be much more satisfying to identify a mode of evaluation of philosophical systems that was distinctively philosophical and illuminated the role of parsimony, unity, etc.

This is related to an important point about two kinds of evaluation. To evaluate something is to assign value to it. Given the distinction between intrinsic and instrumental value, there is a distinction to be drawn between two kinds of evaluation: intrinsic evaluation and instrumental evaluation. Clearly, for any phenomenon $P$ with intrinsic value, we can ask of anything whatsoever whether it has instrumental value in promoting $P$. Accordingly, if we had a list of all 'intrinsic valuables', we could certainly evaluate axiomatizations of total theory for their instrumental value in promoting any or all of them-just as we could evaluate cars or dogs for the same. It is trivial, in this sense, that philosophical systems (still construed as axiomatized total theories) can be instrumentalevaluated.' But this leaves open the question of whether they might also be intrinsicevaluated.

(Relatedly, note the following clear asymmetry between the notions of truthconduciveness and happiness-conduciveness: a theory's truth-conducive features are supposed to enhance the likelihood of the theory itself being true. By contrast, the theory's happiness-conduciveness does not pertain to whether it enhances its own happiness! What it pertains to is the theory's status as conducive to 
something else's happiness. Ideally, we would have a way to evaluate philosophical systems not only for their effects on other things but also for their own features.)

To summarize: while evaluation of axiomatized total theories for happinessenhancement is clearly possible, it is limited in that (i) it provides only for instrumental-evaluation that (ii) does not illuminate the role of the theoretical virtues in the practice of philosophical evaluation. It is accordingly very odd to say that the aim of (traditional analytic) philosophy is to produce happiness-enhancing axiomatizations of the total theory of the world. One might hope that there is some other value $V$, intrinsic rather than instrumental, such that the theoretical virtues are $V$-conducive. It would then be more plausible to say that the aim of (one central project of traditional analytic) philosophy is to produce $V$-ly axiomatizations of total theory.

In the remainder of this section, I want to float the conjecture that $V$ is beauty, or 'aesthetic value' more generically. I will suggest that the most prominent theoretical virtues-parsimony, unity, and elegance-are all beauty-conducive and that, moreover, aesthetic evaluation of competing axiomatizations is intrinsic evaluation. This would provide initial support for the following surprising thesis: the aim of (one central project of traditional analytic) philosophy is to produce aesthetically valuable axiomatizations of the total theory of the world. The thesis is surprising insofar as it casts the aim of philosophy as partly epistemic and partly aesthetic, as opposed to entirely epistemic. I will close by considering the objection that if this were right, it would actually devalue philosophical activity, at least as most philosophers think of it, casting it as a much more lighthearted endeavor than the crushing majority of philosophers take the aim of this central activity of their lives to be.

Parsimony is by far the most prominent of the theoretical virtues. Indeed, parsimony is so central in philosophical practice that often a parsimonious theory is taken to require no further argument: if it can be defended from objections, its parsimonious character motivates it sufficiently. Thus, in his classic defense of the mindbody identity theory, J. J. C. Smart (I959) briefly mentions that materialism is more parsimonious than dualism $(\mathrm{I}<2$ !) and proceeds to defend his version of materialism against seven objections. Such heavy emphasis on parsimony is pervasive in philosophy. But does parsimony render the parsimonious more beautiful? In other domains, we do seem to think so. Consider the parsimony and simplicity we gustatorily appreciate in sushi and carciofi alla giudea, auditorily appreciate in Arvo Pärt and KRS-One, and visually appreciate in minimalist architecture, Ellsworth Kelly paintings, and Muromachi rock gardens. This seems very much an aesthetic appreciation - an appreciation of the relevant items for their aesthetic quality. Thus the property of being parsimonious can very much enhance the aesthetic value of its bearer.

This is not to deny that there is beauty to be found in the lushness of Hawaiian landscapes, the ornate intricacy of baroque architecture, the overwhelming detail of a Walt Whitman poem, the complexity of a Shakespearean character, and so 
on. My claim is that parsimony is beauty-conducive, not that lack of parsimony is ugliness-conducive! As long as there is a specific kind of beauty $B$, such that an item's parsimony bestows $B$ on it, parsimony is shown to be beauty-conduciveeven if the type of beauty it conduces is specific.

There is also a beauty we find in unity: the pleasing symmetries of neoclassical architecture, the carefully crafted cohesion of a Russian novel. Indeed, there is an aesthetic tradition that considers internal unity the be-all and end-all of beauty. Plotinus writes:

We hold that all the loveliness of this world comes by communion in Ideal-Form.... [W] [Were the Ideal-Form has entered, it has grouped and coordinated what from a diversity of parts was to become a unity: it has rallied confusion into co-operation: it has made the sum one harmonious coherence: for the Idea is a unity and what it molds must come into unity as far as multiplicity may. (Ennead I, 6)

Even if we do not take unity to exhaust beauty, it certainly exemplifies beauty. Often its aesthetic appeal is heightened when set against a more disorderly backdrop: this is what is sometimes called 'unity-in-diversity', whereby constant or recurring patterns emerge from a wealth of fluctuating or chaotic elements. We aesthetically appreciate the structure-bestowing underlying theme in Bach's Goldberg Variations, the emerging figures in Seurat's Sunday Afternoon on the Island of La Grande Jatte, the force of Poe's refrain 'nevermore' in The Raven. Nietzsche (I 999) held that beauty just is the right balance between the 'Apollonian' and 'Dionysian' aspects of an artwork, that is to say, the controlled harmony of the whole and the unbridled life-force of its many parts. Again, we need not defend this more ambitious claim to acknowledge that unity-in-diversity does in fact enhance the aesthetic value of that which exhibits it.

Such unity-in-diversity is clearly characteristic of axiomatic systems, where a controlled number of axioms yields the seemingly unruly multitude of theorems. Blanché puts this nicely in his classic on mathematical axiomatics:

[I]n detecting formal analogies, axiomatics reveals unsuspected correspondences between diverse domains of a science, and even parallels between seemingly foreign sciences. In bringing out the invariant structure common to apparently heterogeneous theories, it allows us to dominate them in thought and to embrace in a more synthetic look vast intellectual landscapes that formerly were known only fragmentarily. (Blanché I95 5: 77-78, my translation)

This is why Hutcheson maintained that Euclid's axioms are the most beautiful objects. But more generally, Hutcheson maintained that beauty is encoded in 'the Knowledge of some great Principles, or universal Forces, from which innumerable Effects do flow' (Hutcheson 2004: 38). Presumably, the scrutability base of the theory of everything would provide the most general principles, those that unify 
the rest of reality. This kind of unity-in-diversity is clearly exhibited by the major philosophical systems, whose very point is to take the bewildering totality of the cosmos and produce the order and systematicity that would render it intelligible.

(In a way, the very start of philosophy is with the idea that appearance is multiple but underlying reality is one: what Thales offered us is a theory of everything in terms of a single fundamental principle, water. Later philosophical systems were thankfully more sophisticated, but they tended to retain this aspiration for unity-in-diversity. Kant's well-known system offers unified accounts of the true, the good, and the beautiful that ground them in synthetic a priori principles of pure theoretical reason, pure practical reason, and the pure faculty of judgment, respectively. Franz Brentano's lesser-known system offers unified accounts of the true, the good, and the beautiful in terms of fitting belief, fitting approval, and fitting delight, respectively, all known through inner perception. There is a diversity in both systems, of faculties or of types of intentional act, but there is also unity in each, in the form of the recurrent appeal to synthetic a priori principles or to inner-perceptible fittingness.)

It is beyond question that elegance is beauty-conducive. Indeed, elegance appears to just be one species of beauty. It is an interesting and nontrivial question what the distinguishing characteristic of this species is. I have no general answer to this question, but I note that simplicity and unity appear to be aspects of elegance. Certainly the idea of restraint, or control, is central to elegance, as when a ballet adagio strikes us as elegant. This kind of restraint manifests itself typically through simplicity and minimalism: a flamboyant dress can be beautiful, but not by being elegant; an elegant dress would have a limited number of components relating to each other in a readily tractable manner. In any case, elegance appears to be inherently manmade: the Luxembourg Gardens in Paris are elegant, but it would be odd to describe a similarly structured wild field as elegant. This suggests that elegance is the expression of conscious agency, which produced the simplicity and unity of the elegant item. In characterizing a philosophical theory as elegant we likewise appear to commend the philosopher's agency in creatively devising a simple and unified account of apparently complex and diverse phenomena.

To summarize, parsimony and unity(-in-diversity) are beauty-conducive in that there is a kind of beauty that their possession enhances, and elegance is beautyconducive in that it is itself a species of beauty. In fact, one might surmise that elegance is precisely the kind of beauty that is enhanced by parsimony and unity. Insofar as we evaluate philosophical systems (i.e., axiomatized total theories) in terms of parsimony, unity, and elegance, then, we seem to evaluate them aesthetically; that is, we evaluate them for possession of (a specific species of) beauty. We may put this as follows:

AESTHETIC Standard intrinsic-evaluation of axiomatizations of total theories in terms of parsimony, unity, and elegance is aesthetic evaluation. 
On the proposal here being made, the project of total axiomatics, or serious metaphysics, is fully characterized by the conjunction of four claims: COMPLETE, Discriminate, entail/scrutable, and Aesthetic. This provides an initial motivation for the thought that the aim of philosophy, as far as one central project of traditional analytic philosophy (total axiomatics) is concerned, is to produce axiomatizations of the theory of everything that exhibit the relevant species of beauty to the highest degree possible. In a slogan: the aim of (traditional analytic) philosophy is to produce maximally elegant axiomatizations of total theory

It might be objected that the only reason we value beauty is that it (or the witnessing of it) enhances happiness, so ultimately the beauty-conducive character of the theoretical virtues is itself only instrumentally valuable. But this is a confusion: perhaps the only reason we ethically value beauty is for its happiness-enhancement, but we certainly do not aesthetically value beauty for its happiness-enhancement. There is nothing we aesthetically value beauty for-beauty is what we aesthetically value, or rather what we evaluate for. In this sense, aesthetic evaluation of philosophical systems is intrinsic evaluation: it is the assignment of an intrinsic (aesthetic) value to these systems.

Another objection might be that for some theoretical virtues, beauty-conducing is not so evident. Modesty and testability, for example, do not seem to be particularly beauty-conducive, and in a way nor do fecundity and conservatism. It is noteworthy, however, that these virtues are much less frequently appealed to by philosophers than parsimony, simplicity, unity, and elegance. The latter form the real core of theory-choice in philosophy. The former seem to show up originally in the evaluation of scientific theory, and only by a kind of uncritical propagation are sometimes applied to philosophical-theory evaluation. Indeed, this may be taken as a strength of the current proposal: the fact that some theoretical virtues are clearly beauty-conducive while others are not explains why the former are prominent in philosophical practice whereas the latter are not.

A third objection might be that aesthetic evaluation of philosophical systems is pointless, given that 'beauty is in the eye of the beholder'. One response here is to celebrate the ensuing relativism, perhaps even use it to explain why philosophical disputes seem fundamentally unlike scientific disputes in admitting more than one correct resolution (Benovsky 20I3). Another response is to adopt a thoroughgoing objectivism about aesthetic value that grounds aesthetic evaluation in objective, mind-independent facts about what is more beautiful than what. A third responsemost plausible, it seems to me-is to suggest that while aesthetic disagreements are sometimes brute and irresolvable, this is not always or even typically the case. Compare the sounds of an airplane flying overhead and Bach's Cello Suite No.I, or your backyard and the Luxembourg Gardens. It seems perfectly reasonable, indeed fitting for creatures like us, to prefer aesthetically the second in each pair. We may say that there are agent-neutral reasons to aesthetically prefer Bach to the airplane and the Luxembourg Gardens to your backyard. At the same time, there appear to be no agent-neutral reasons for aesthetically preferring Bach's Cello Suite No.I over the Luxembourg Gardens or the other way round-here the preference seems 
indeed 'subjective' in the relevant sense. By the same token, some philosophical systems may be aesthetically preferable to others even if there is no single best system. (A good model for this is Hume's ideal observer account of beauty: an ideal observer would likely aesthetically prefer some philosophical systems over others, but it is an open question whether there will turn out to be one specific philosophical system $\varphi$, such that all ideal observers would converge on preferring $\varphi$ to every other system. Even if there is not such a system, aesthetic evaluation of competing philosophical systems is far from pointless, admitting of correct or justified value-discriminations.)

A fourth objection: aesthetic values supervene on nonaesthetic facts, so ostensibly aesthetic evaluation of philosophical theories is ultimately just evaluation with respect to subvening nonaesthetic facts. However, arguably the supervenience base of philosophical beauty consists simply of the aforementioned beautyconducive theoretical virtues. Aesthetic evaluation of philosophical systems does proceed by comparison of theoretical virtues. But it does not follow that the evaluation is not genuinely aesthetic. The theoretical virtues do not themselves tell us why scoring high on them is valuable. They do not tell us, that is, what value(s) they conduce (that is why we had to search for the value $V$ that they conduce). It is only when we appreciate their beauty-conducive character that we can see why and in what sense a philosophical system's theoretical virtues make it valuable.

A final objection is that most philosophers would be strongly dismayed by the notion that what they pursue is some sort of intellectual beauty. Convinced on their deathbed by the argument of this paper, some might consider that their life's work has been in vain-they have been laboring under a misapprehension, in complete self-alienation, the whole time. Now, even if the aim of philosophy need not be transparent to philosophers, the objector may press, surely the pursuit of philosophy should be able to survive reflective understanding of its own nature. This objection relies on a mischaracterization of our proposal. There is no claim here that philosophy is a purely aesthetic activity. On the contrary, the basic, foundational philosophical activity is axiomatization-a purely cognitive activity whose import is entirely epistemic. Our suggestion is only that philosophy also involves an aesthetic dimension, more seldom noticed. We highlight this aesthetic dimension here because of its role in supplementing COMPLETE, DISCRIMINATE, and ENTAIL/SCRUTABLE in a full characterization of the relevant philosophical project, and that supplementation is the topic of this paper. All the same, at bottom the project thus fully characterized is more essentially epistemic than aesthetic: an elegantly axiomatized total theory of the world presents the truth, though it presents it beautifully.

In addition, I suspect that philosophers who take a claim of aesthetic dimension in the aim of philosophy as somehow devaluing philosophy are selling aesthetic productivity short. Consider Dante's Divine Comedy and what its creation has contributed to the world-and all the millions of humans it has fittingly delighted since its creation seven centuries ago. If it turned out that Kant's three-critique system contributed to the world something cut of the same cloth as Dante's three-cantica masterpiece, this could be rightly seen as uplifting rather than dispiriting news. In 'The Elimination of Metaphysics', Carnap (I932) claimed 
that metaphysicians were 'musicians without musical ability'. The present view, in contrast, is that (serious-)metaphysicians are musicians with musical ability. Their collective labor results in the limning and refining of certain abstract structures of great beauty. Nobody can produce an elegant digestible theory of everything like a philosopher. Humanity must rely on this narrow band of individuals to produce these beautiful abstract structures, just as it must rely on a small group of individuals to produce beautiful paintings; and in its wisdom it has set aside funds to enable philosophers to pursue this creative activity in relative calm, just as it has set aside funds to enable choreographers to belabor gesture-sequences in relative serenity.

\section{Conclusion: The Aim(s) of Philosophy}

What is the telos of philosophical inquiry? What intellectual goods can we expect from it? I have suggested that there may be too many philosophical traditions, branches, and programs to expect a single overarching aim to characterize all intellectual activity legitimately described as philosophical. I have accordingly focused on one central project irrigating much of traditional analytic philosophy (and recently articulated with considerable precision by Frank Jackson and David Chalmers). This is the project of finding ways to express a complete theory of the world in terms of a limited range of fundamental notions. I have suggested that we think of this project in analogy to axiomatization projects in mathematics, indeed that we conceive of it as total axiomatics: the project of axiomatizing the total theory of the world. I have argued that the aim of this project-the intellectual good it stands to produce-is the development of beautiful, or more specifically elegant, axiomatizations of the theory of everything. The thesis is intended to be revisionary: philosophers do not typically conceive of their work as aiming at the production of beautiful objects, but I have argued that, all the same, the kind of intrinsic value this type of philosophical activity maximizes is not epistemic (the true) or ethical (the good), but aesthetic (the beautiful).

If this is right, then a more self-conscious pursuit of the project would divide it into three chapters (doubtless intermingled in practice). The first chapter would concern the formulation of a total theory of the world, mostly by synthesizing work from outside philosophy (though quite possibly also by completing it from within philosophy, for example in normative domains). The second chapter would concern finding ways to axiomatize the total theory produced in the first, that is, producing minimal scrutability bases for it. The third would aesthetically evaluate competing axiomatizations, in an attempt to identify the one or handful most beautiful among them-by applying the standard criteria of philosophical theory-choice to do with parsimony, unity, and so on. Together, these constitute a project both intellectual and aesthetic-what we might call the art of total axiomatics. 


\section{References}

Benovsky, J. (20I3) 'Philosophical Theories, Aesthetic Value, and Theory Choice'. Journal of Value Inquiry, 47, I9I-205.

Blanché, Robert. (1955) L'axiomatique. Paris: Presses Universitaires de France.

Bourbaki, Nicolas. (1970) Éléments de mathématique. Paris: Hermann.

Bovens, Luc, and Stephan, Hartmann. (2003) Bayesian Epistemology. Oxford: Oxford University Press.

Carnap, R. (1932) 'The Elimination of Metaphysics through Logical Analysis of Language'. Erkenntnis, 2, 2I9-4I. Reprinted in S. Sarker (ed.), Logical Empiricism at Its Peak. Translated by A. Pap (New York and London: Garland Publishing, I996), IO-32.

Carnap, R. (I950) 'Empiricism, Semantics, and Ontology'. Revue Internationale de Philosophie, $4,20-40$.

Castaneda, Héctor-Neri. (I980) On Philosophical Method. Bloomington, IN: Nous Publications.

Chalmers, David J. (2009) 'Ontological Anti-Realism'. In David J. Chalmers, David Manley, and Ryan Wasserman (eds.), Metametaphysics (Oxford and New York: Oxford University Press), 77-I 29.

Chalmers, David J. (2OI2) Constructing the World. Oxford and New York: Oxford University Press.

Hutcheson, Francis. (2004) An Inquiry into the Original of our Ideas of Beauty and Virtue. Indianapolis, IN: Liberty Fund. First published 1725.

Jackson, Frank C. (1998) From Metaphysics to Ethics: A Defence of Conceptual Analysis. Oxford: Clarendon Press.

Kriegel, U. (2013) 'The Epistemological Challenge of Revisionary Metaphysics'. Philosophers' Imprint, $\mathrm{I} 2, \mathrm{I}-30$.

Kriegel, U. (2015). 'Total Axiomatics and Philosophical Practice'. Unpublished manuscript.

Levine, J. (I983) 'Materialism and Qualia: The Explanatory Gap'. Pacific Philosophical Quarterly, $64,354-6 \mathrm{I}$.

Nietzsche, Friedrich. (1999) The Birth of Tragedy. Trans. R. Speirs. Cambridge, UK: Cambridge University Press. First published 1872.

Pasch, Moritz. (I 882) Vorlesungen über neuere Geometrie. Leipzig: Teubner.

Peano, Giuseppe. (г889) Arithmetices principia, nova methodo exposita. Turin: Bocca.

Pieri, M. (I900) 'Della geometria elementare come sistema ipotetico deduttivo'. Monografia del punto e del moto: Memorie della Reale Accademia delle Scienze di Torino, 49, I73-222.

Plotinus. (1952). The Six Enneads. Translated by S. McKenna and B. S. Page. Chicago: Encyclopedia Britannica Publishing.

Schlimm, D. (20I3) 'Axioms in Mathematical Practice'. Philosophia Mathematica, 2I, 37-92.

Skyrms, B. (I98I) 'Tractarian Nominalism'. Philosophical Studies, 40, I99-206.

Smart, J. J. C. (I959) 'Sensations and Brain Processes'. Philosophical Review, 68, I4I-56.

Sober, E. (2009) 'Parsimony Arguments in Science and Philosophy: A Test Case for Naturalism $\mathrm{p}$ '. Proceedings and Addresses of the American Philosophical Association, 82, I I7-55. 